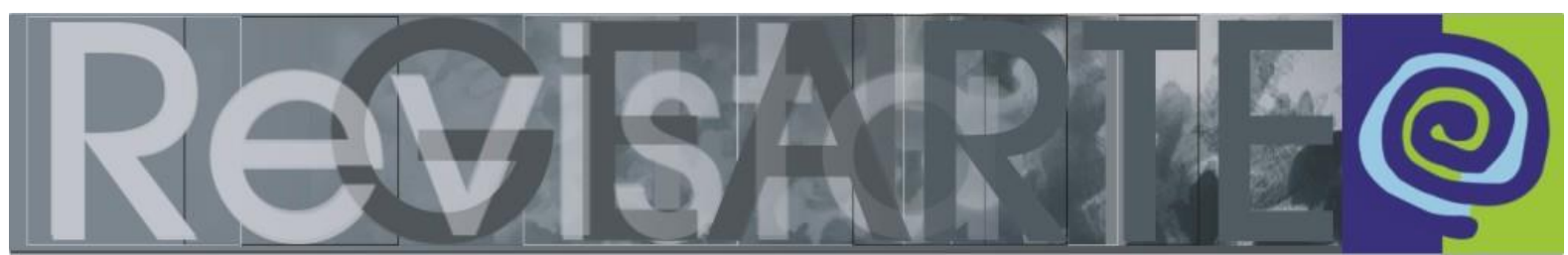

ISSN 2357-9854

\title{
Práticas e técnicas corporais promovendo a presença de artistas com deficiência na cena contemporânea
}

\author{
Marcia Berselli (Universidade Federal de Santa Maria - UFSM, Santa Maria/RS, Brasil)
}

\begin{abstract}
RESUMO - Práticas e técnicas corporais promovendo a presença de artistas com deficiência na cena contemporânea - A ampliação do acesso de artistas com deficiência às artes da cena pode ser possibilitada a partir da flexibilização de algumas técnicas e práticas, bem como da emergência de práticas baseadas em pressupostos menos restritivos. O presente artigo apresenta uma reflexão sobre práticas e técnicas corporais reconhecidas enquanto somáticas podendo se fazer presentes em processos criativos de modo a promover a presença de artistas com deficiência na cena. Abordando a acessibilidade pelo aspecto atitudinal, as práticas corporais são reconhecidas enquanto acessíveis não só pelos modos flexíveis de abordagens do movimento, mas, principalmente, pela proposição de interação entre os participantes que mobiliza dinâmicas de privilégio e poder.
\end{abstract}

PALAVRAS-CHAVE

Práticas corporais. Artistas com deficiência. Acessibilidade atitudinal. Artes Cênicas.

ABSTRACT - Corporal Practices and techniques fomenting the presence of disabled artists in the contemporary scene - Enlargement access of disability artists to the performing arts can be made possible from the easing of some techniques and practices, as well emergency of practices based on less restrictive assumptions. This article presents a reflection about corporal practices and techniques recognized as somatic that can be present in the creative process in order to promote the presence of artists with disabilities on the stage. In approaching accessibility by the attitudinal aspect, bodily practices are recognized as accessible not only by the flexible modes of movement approaches, but mainly by the proposition of interaction between participants that mobilizes dynamics of privilege and power.

\section{KEYWORDS}

Corporal practices. Disability artists. Attitudinal accessibility. Performance arts.

As artes da cena são tradicionalmente reconhecidas enquanto espaço promotor de questionamento e reflexão. Naturalmente provocador, o palco já foi o local da catarse, purgando as emoções dos espectadores na representação trágica que confirmava o poder do destino sobre os homens; bem como seu contrário, espaço didático e dialético, incitando os espectadores à ação de modo a modificar contextos sociais de injustiça e abuso de poder. Território da diferença, controversamente o palco ainda não é de todo acessível, pois limita a participação de seus agentes. Se, rapidamente, realizarmos um exercício de memória pelo qual buscamos recuperar imagens dos últimos espetáculos a que assistimos, provavelmente poderemos esboçar um padrão corporal. Encontraremos, provavelmente, o mesmo padrão se 
ampliarmos nosso exercício, rememorando, agora, espaços de ensino de teatro ou dança, através de workshops a que tivemos possibilidade de participar ou exercícios de jovens artistas em formação que tenhamos presenciado. Tal perspectiva indica o perfil que será encontrado nas escolas de teatro e de dança das instituições de ensino superior.

Nesse sentido, encontrar espaços relativos a atividades cênicas acessíveis para pessoas com deficiência, por exemplo, é tarefa árdua e nem sempre com resultados que condizem com as propostas de acessibilidade e inclusão disseminadas pelos discursos atuais, contradição do espaço plural que as artes da cena se propõem a ser. Desse modo, mais do que analisar as causas da manutenção desses padrões corporais - exercício importante e necessário - proponho, neste texto, uma análise de práticas corporais reconhecidas enquanto abordagens somáticas do movimento, de modo a refletir sobre como sua utilização pode promover a ampliação do acesso de artistas com deficiência às artes da cena.

Após uma breve abordagem sobre o contexto de desenvolvimento dos métodos de Educação Somática, apresento o Método Feldenkrais, desenvolvido por Moshe Feldenkrais na década de 1950. Abordo, também, o Contato Improvisação, forma de dança desenvolvida por Steve Paxton junto a outros colaboradores na década de 1970, e que compartilha princípios com métodos de Educação Somática. Analisando as duas práticas, proponho uma reflexão sobre sua utilização por grupos compostos por pessoas com e sem deficiência. O objetivo deste trabalho é apresentar práticas corporais alinhadas com as perspectivas da acessibilidade, principalmente em seu aspecto atitudinal.

\section{Acessibilidade}

Identifico e apresento, neste texto, algumas práticas por considerá-las menos restritivas e, dessa forma, acessíveis a pessoas com deficiência. No entanto, a reflexão aqui apresentada não esgota o assunto, e outras práticas podem ser analisadas mantendo o foco na questão da acessibilidade. Destaco, ainda, a crença de que as práticas corporais possam ser ajustadas e, de certa maneira, reformuladas a partir de cada praticante, fato que possibilita a transformação de práticas mais 
rígidas de acordo com os interesses dos que dela se aproximam. Porém, para tanto, é necessário desenvolver um olhar alargado sobre padrões de eficiência que determinam e avaliam o corpo em ação na cena, ampliando ou reduzindo seu acesso. No que tange à acessibilidade, é importante reconhecer a amplitude das dimensões que a constituem.

No preâmbulo da Convenção Internacional sobre os Direitos das Pessoas com Deficiência (BRASIL, 2009, s/p), há o reconhecimento de que a "deficiência resulta da interação entre pessoas com deficiência e as barreiras devidas às atitudes e ao ambiente que impedem a plena e efetiva participação dessas pessoas na sociedade". Há assim uma transformação das perspectivas em relação à deficiência que reconhece as barreiras não só físicas, mas sociais. Colocando em evidência a interação com o ambiente social, o documento faz referência ao modelo social da deficiência. Tal modelo diferencia-se do modelo médico apontando a uma mudança na base dos modos de representação sobre a pessoa com deficiência. $O$ modelo social da deficiência inverte o lado a ser corrigido: aqui, é o ambiente que deve ser transformado.

Se o modelo médico localiza a deficiência na pessoa com deficiência e na sua aberração específica, o modelo social da deficiência altera radicalmente a mentalidade, os pontos de referência para o conhecimento. No modelo social, a deficiência é aparente na interação entre a pessoa com deficiência e o ambiente social. [...] Dentro destes termos, a deficiência se torna uma questão social e ambiental e não médica (KUPPERS, 2014, s/p).

Enquanto o modelo médico localiza a deficiência na pessoa com deficiência, no modelo social a deficiência é aparente na interação entre a pessoa com deficiência e o ambiente. A acessibilidade, então, não se restringe apenas à livre circulação ou à questão arquitetônica, mas também as dimensões "comunicacional, metodológica, instrumental, programática e atitudinal" (VENDRAMIN, 2013, p. 2). Nesse sentido, a acessibilidade em um processo de criação cênica diz respeito a práticas que são desenvolvidas fundadas em modos e meios com características que as tornam acessíveis. Isso significa não só um movimento no sentido de transformação metodológica, mas também relacional, de comportamentos, posturas e modos de agir. 


\section{As abordagens somáticas do movimento}

Refletindo sobre práticas corporais menos restritivas, encontro, nas nomeadas práticas somáticas, uma possibilidade de acesso facilitado às mais diversas organizações e possibilidades corporais.

Primeiramente, cabe destacar que o entendimento do corpo como soma compreende a não separação do dualismo corpo-mente, além de não reconhecer o corpo apenas em seu aspecto biológico, mas leva em conta aspectos da ordem de emoções, pensamento, valores sociais, culturais, políticos e espirituais.

O movimento contrário ao dualismo cartesiano marca as origens da educação somática ocidental. A concepção de uma divisão entre corpo e alma, reconhecendo a inteligência e a atividade intelectual como uma faculdade do espírito ou da alma não subordinada ao corpo, é a tese de que o ser humano é constituído por corpo e mente enquanto substâncias distintas e incompatíveis. O entendimento de corpo como soma caminha na direção oposta e compreende o corpo em sua integridade. Glena Batson (2009) reconhece François Delsarte, Emile Jaques Dalcroze e Bess Mensendieck como pioneiros das práticas somáticas a partir do movimento europeu Gymnastik, do final do século XIX. Esses pioneiros buscavam uma abordagem mais natural do movimento ao unir mente e corpo, por meio da respiração, toque e movimento e questionaram a ideologia tradicional do rigor no treinamento físico (BATSON, 2009).

Porém, o termo somatics foi proposto por Thomas Hanna apenas nos anos de 1970. Hanna era filósofo e praticante do Método Feldenkrais. Somatics deriva da palavra grega soma e significa o corpo em sua totalidade, corpo enquanto experiência vivida, em constante (e única para cada sujeito) relação com aspectos externos. Compreender o corpo como soma é tomar a perspectiva interna de percepção do corpo, em uma relação entre consciência, biológico e meio ambiente (HANNA, 1983).

Os praticantes de métodos de educação somática desenvolveram seu trabalho, no início do século $\mathrm{XX}$, por meio da observação dos próprios comportamentos de movimentos e sinais corporais. Alguns exemplos são Elsa Gindler com a psicoterapia 
corporal $^{1}$, Gerda Alexander com a Eutonia e Frederick Matthias Alexander com a Técnica Alexander (BATSON, 2009). Esses reformadores do movimento desenvolveram suas práticas buscando sanar seus próprios problemas e complicações corporais advindas de doenças ou acidentes. O mesmo pode ser citado para Moshe Feldenkrais com o Método Feldenkrais ${ }^{\circledR}$, Bonnie Bainbridge Cohen com o Body-Mind Centering ${ }^{\circledR}$ e Judith Aston com a Aston ${ }^{\circledR}$ Kinetics. Tal dado informa sobre a importância da observação de como cada corpo funciona em sua estrutura, reconhecendo as possíveis causas dos problemas físicos de cada praticante para promover mudanças por meio de ajustes sensíveis nas movimentações e posturas diárias do corpo.

Utilizadas enquanto recurso para tratar traumas e lesões, assumindo um caráter reabilitatório, as práticas somáticas logo passaram a encontrar espaço no campo da dança. Segundo Batson (2009, p. 01), a área da dança passa a ter um interesse real na educação somática a partir de uma série de 1980 da Dance Magazine sobre "Terapias corporais" de autoria de Martha Myers. Os currículos de dança passaram a incluir práticas exploratórias guiadas, sendo que:

\begin{abstract}
Estas abordagens mais corporificadas adicionaram uma nova dimensão para a investigação do corpo (corpo-como-conteúdo) além de estudos em ciências clássicas da anatomia, cinesiologia e biomecânica. O século XX também se caracterizou por fronteiras mais porosas dentro da educação da dança, com influências do Contato [Improvisação] e outras formas de improvisação, Skinner Release Technique e outras formas de "Release" (por exemplo, derivado de Trisha Brown), dança étnica, artes marciais e performances circenses, para citar alguns. Não apenas explorações de movimentos individuais e colaborativos, como também imagens, toque, voz, música e até mesmo tecnologia, puderam tornar-se o estímulo criativo primário para ajudar a expandir a arena da formação [treinamento] do corpo-mente (e portanto da dança) (BATSON, 2009, p. 01, trad. nossa).
\end{abstract}

As práticas somáticas modificaram de certa forma a pedagogia da dança ao deslocarem o interesse da forma do movimento para as percepções e estímulos sensoriais do praticante. Através da auto-observação e exploração individual de movimentos, cada praticante tem a oportunidade de descobrir seu corpo, suas

1 Elsa Gindler foi professora de movimento alemã. Não há praticamente registros escritos de seu trabalho, no entanto, sua prática influenciou muitos profissionais. Um exemplo é a Ginástica

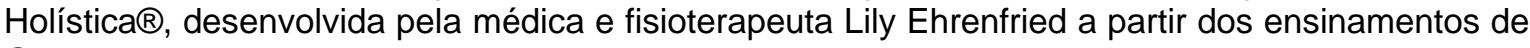
Gindler. 
possibilidades e assim passar por um real reconhecimento de seus recursos corporais. Na contramão das técnicas pautadas pelo virtuosismo do movimento e do corpo, técnicas corporais que poderiam limitar o corpo em uma rigidez de movimentos, as práticas somáticas se diferenciam ao buscar a disponibilidade corporal.

A noção de corpo disponível aponta também às características das técnicas de educação somática de acolher os corpos trabalhando a partir de suas possibilidades reais. A busca de como o movimento acontece em cada corpo também distingue as práticas somáticas de outras técnicas fortemente implicadas em uma determinada estética que conduz a pressupostos mais rígidos pautados em formas de execução corretas ou incorretas do movimento.

\section{Feldenkrais e Contato Improvisação: práticas de relação}

Moshe Feldenkrais, criador do método somático que leva seu nome, desenvolveu duas abordagens de aplicação da técnica - "Consciência corporal pelo movimento" e "Integração Funcional". Feldenkrais, graduado em engenharia mecânica e elétrica, e com doutorado em física, aliou seus conhecimentos em física, engenharia, judô e psicologia para desenvolver suas abordagens do movimento e, a partir da década de 1950, passou a formar grupos de alunos em seu método.

A abordagem "Consciência pelo movimento" relaciona-se ao entendimento de que "nós agimos de acordo com nossa autoimagem" (FELDENKRAIS, 1977, p. 19). Assim, a prática está baseada no autoconhecimento corporal e no reconhecimento de nossos hábitos. "Cada um de nós fala, se move, pensa e sente de modos diferentes, de acordo com a imagem que tenha construído de si mesmo com o passar dos anos. Para mudar nosso modo de ação, devemos mudar a imagem própria que está dentro de nós" (FELDENKRAIS, 1977, p. 27). A autoimagem está relacionada a ativação de certas células e, durante o desenvolvimento do indivíduo na sociedade, muitas células permanecem inativas. A organização de nossas sociedades ocidentais promove que busquemos aprender algo até atingir um objetivo definido, sendo que tal aprendizagem está ajustada a circunstâncias específicas de cada contexto social. Assim, tão logo o objetivo é alcançado, a aprendizagem cessa levando a uma limitação do desenvolvimento de habilidades em relação ao nosso potencial. 
A mesma perspectiva é observada quando o indivíduo encontra dificuldades para realizar algumas tarefas, fato que o leva a estabelecer limites para suas potencialidades baseado na crença de que "nunca conseguirá aprender tal coisa" ou que "não consegue realizar tal tarefa". Tal aspecto está relacionado a circunstâncias sociais e econômicas, variando de acordo com cada contexto.

\begin{abstract}
A tendência biológica de qualquer organismo para crescer e desenvolver-se plenamente, tem sido grandemente governada pelas revoluções sociais e econômicas, que melhoraram as condições de vida para a maioria e capacitaram um maior número a conseguir um mínimo de desenvolvimento. Sob tais condições, o desenvolvimento potencial básico cessa no início da adolescência, na medida em que a demanda da sociedade capacita os membros da jovem geração a serem aceitos como indivíduos úteis (FELDENKRAIS, 1977, p. 34).
\end{abstract}

Porém, Feldenkrais destaca que "nossa autoimagem nunca é estática. Ela muda de ação para ação, mas estas mudanças gradualmente tornam-se hábitos, isto é, as ações tomam caráter fixo, imutável" (FELDENKRAIS, 1977, p. 28). Ainda, os indivíduos costumam realizar um autojulgamento e uma identificação de sua autoimagem de acordo com seu valor para a sociedade. Tal perspectiva reforça a manutenção dos padrões, que promovem uma sociedade formada por indivíduos com objetivos e comportamentos parecidos, dado que qualquer mudança poderia provocar a diminuição do valor de tais indivíduos. As necessidades particulares são negadas na busca pela adaptação de acordo com as normas gerais impostas pelos determinados contextos sociais.

Feldenkrais (1977, p. 36) utiliza essa perspectiva da sociedade de modo a reconhecer a influência da atitude dos indivíduos em relação a si mesmos quando da resolução pela busca do desenvolvimento e plenitude de suas qualidades específicas. Porém, o desenvolvimento de si está intrinsecamente relacionado ao reconhecimento do valor de si. Para uma melhora da autoimagem faz-se necessário aprender a valorizar-se como indivíduo (FELDENKRAIS, 1977).

Assim, os exercícios propostos no método "Consciência pelo movimento" conduzem o praticante a um maior conhecimento de si mesmo, e a uma descoberta de suas potencialidades, de seus recursos pessoais que, sem terem sido desenvolvidos, eram desconhecidos. As atividades são conduzidas verbalmente e 
realizadas em grupo, no entanto, cada praticante desenvolve os movimentos a seu próprio modo, de acordo com as suas possibilidades como uma exploração individual. O interesse está na trajetória do movimento e não no seu final. O foco não é atingir objetivos, mas perceber como cada corpo, cada organização corporal desenvolve os movimentos. A atenção é colocada sobre a trajetória dos movimentos, sendo que a pergunta não está centrada em "o que" o corpo faz, mas sim no "como" ele faz.

Ao reconhecer que hábitos inconscientes conduzem nossas formas de agir cotidianamente, no decorrer da prática, o praticante vai tomando consciência sobre os movimentos realizados pelo corpo em cada pequena ação, verificando tensões desnecessárias, identificando as melhores posturas e ampliando as percepções de si mesmo. O reconhecimento de si mesmo parece ser aspecto fundamental para o estabelecimento de relações com os demais. Ao ampliar suas possibilidades e desenvolver a consciência sobre suas efetivas potencialidades, a abordagem somática aqui destacada auxilia os praticantes a se tornarem aptos a uma troca com os demais que não está pautada em seus limites, mas sim em suas capacidades.

$\mathrm{Na}$ esteira das práticas somáticas, o Contato Improvisação (Cl) também enfatiza as percepções do praticante e seu envolvimento com o desenvolvimento do movimento em detrimento à forma. O próprio desenvolvimento da dança, no $\mathrm{Cl}$, é privilegiada não a visão, mas o toque na troca de peso enquanto os praticantes utilizam todos os sentidos para se orientarem no espaço.

Uma diferença básica entre a técnica contato-improvisação e a dança
moderna e clássica é que a base da primeira está no peso e no toque no
outro, enquanto na segunda, a base é sobre a potência de uma performance.
O contato-improvisação é mais uma prática do que uma performance, e
assim, de alguma maneira, tira os dançarinos da relação social em que eles
são o centro. Não importa qual seja o sexo ou a condição do corpo, pois a
técnica não é muito estilizada, nem muito rígida em sua fórmula (PAXTON,
$2006, \mathrm{~s} / \mathrm{p})$.

Por sua característica de prática flexível e adaptável, a partir das possibilidades de cada praticante (ao não apresentar, por exemplo, passos ou movimentos prédeterminados a servir de exemplo para ser repetido), o $\mathrm{Cl}$ se apresenta enquanto uma prática possível de ser realizada independente de prioridades individuais. É importante destacar que o questionamento sobre quais os corpos habilitados à dança marca o 
início do $\mathrm{Cl}$, enquanto estratégia física de resistência aos movimentos dominantes na dança. No desenvolvimento dos movimentos, em um trabalho somático, os praticantes descobrem seus limites e potencialidades e são os envolvidos na dança que encontram ritmo e formas possíveis, sem haver uma liderança de apenas uma das partes.

As características da prática, desse modo, a torna acessível a corpos nas mais diversas estruturas e possibilidades.

\begin{abstract}
Percebemos que as pessoas em cadeiras de rodas poderiam praticar essa fórmula, de uma maneira que a cadeira se torne uma extensão de seus corpos. Ou seja, dança-se a entidade completa: a cadeira e o corpo. Porque o contato-improvisação é baseado no toque em vez do olhar, e através do toque acontece essa troca de peso. Nós procuramos muito para descobrir qual é a troca entre o portador de deficiência e o não portador. Pessoas como o diretor norte-americano Alito Alessi vêm refinando seu método de trabalho por muitos anos, para ter em suas aulas qualquer tipo de pessoa: cegos, surdos, autistas, pessoas com paralisia e com danos cerebrais. Isso existe no balé? Nada disso tem a ver com a perfeição, mas sim com a lógica dessa técnica em particular. Por enquanto, ainda não se usa uma técnica específica para receber essas pessoas na dança, mas o contato-improvisação oferece uma técnica para trabalhar qualquer tipo de corpo, por isso funciona com eles (PAXTON, 2006, s/p).
\end{abstract}

Assim, alguns pesquisadores reconhecem, na prática, uma possibilidade potente para o trabalho em grupos com pessoas com e sem deficiência (ALMEIDA, 2012; AMIR, 2011; TEIXEIRA, 2010; TURSI, 2014). Nas dinâmicas de interação física, o Contato Improvisação propõe uma relação de proximidade entre os parceiros da dança que implica o reconhecimento do outro e permite que as distinções entre eu e o outro sejam confundidas. Este fato leva, por consequência, a "desafiar as noções convencionais de identidade e geografia e cria uma experiência somática que reconstrói a partir de dentro as noções que temos de alteridade2" (ALBRIGHT, 2001, p. 40).

Nesse sentido, há uma concordância destacada nas práticas somáticas sobre a importância do reconhecimento das imagens construídas dos nossos corpos e, assim, inevitavelmente, de nossas potencialidades. Segundo Feldenkrais (1977), nossa autoimagem é condicionada por três fatores: hereditariedade, educação e

Tradução nossa. 
autoeducação. Para Feldenkrais, destes fatores, apenas a autoeducação estaria em nossas mãos, e mesmo ela tenderia a colocar nosso comportamento em concordância com os demais. Dessa maneira, fatores sociais e culturais seriam responsáveis, em grande medida, por nossa construção corporal. Albright, tratando do Contato Improvisação, concorda que "os corpos são profundamente moldados pelas atitudes culturais e pelas condições econômicas" (ALBRIGHT, 2001, p. 40).

Desse modo, o Contato Improvisação, por meio da flexibilização das regras rígidas que determinam as habilidades necessárias ao dançarino, estimula os participantes a observar potencialidades a partir de um ponto de vista diferenciado, destacando as possibilidades e encarando as diferenças enquanto mote potente de criação no encontro de corpos que o Contato determina.

Para cada um dos parceiros, o contato constitui a possibilidade de coexistência de forma e espontaneidade, regras-do-jogo e dança, causa e efeito, centro e margem, proximidade e distância. É o "jogo" dentro da obstinada fixidez de identidades corporais, é dar, é complemento, é différance: as fronteiras instáveis onde uma ética da alteridade ocorre (WILLIANS apud ALBRIGHT, 2001 p. 44).

Interessado justamente em como os praticantes resolvem a dança a partir de movimentos que dependem das singularidades de cada corpo, não são as determinações eu / outro que prevalecem, as determinações binárias não encontram espaço na dança.

O contato-improvisação não se preocupa se uma pessoa é forte e outra é fraca. A técnica está interessada na solução da equação da fraqueza versus necessidade de força e da deficiência do conjunto em geral. Não é sobre quão rápido, alto, forte, flexível o indivíduo é, esses não são os pontos. O ponto é sobre a qualidade de uma parceria, não a quantidade (PAXTON, 2006, s/p).

A parceria, citada por Paxton, faz referência à relação estabelecida entre os praticantes. Tratar de parceria e relação me faz retornar ao ponto abordado no início deste texto acerca da acessibilidade. Anteriormente, ponderei que a acessibilidade em um processo de criação cênica depende de transformações relacionais. Desse modo, faço referência à acessibilidade em seu aspecto atitudinal. Reconhecida enquanto base dos demais aspectos da acessibilidade, a acessibilidade atitudinal

3 Tradução nossa. 
deve ser encarada como princípio primeiro de qualquer processo que se proponha de amplo acesso. Isso porque ela trata do aspecto de comportamentos, de interações possíveis entre sujeitos.

Quando assuntos relacionados à pessoa com deficiência são abordados, é impossível esquecer que um dos maiores entraves ainda diz respeito à segregação social que ocorre também pelo aspecto atitudinal. Por muito tempo mantidas à margem da sociedade, muitas vezes as pessoas com deficiência enfrentam preconceitos pelo desconhecimento da sociedade em relação às questões da deficiência. A partir das práticas aqui referenciadas, Método Feldenkrais e Contato Improvisação, reconhecemos abordagens do movimento que promovem a percepção corporal dos praticantes, levados a uma valorização de si e de suas capacidades que, por sua vez, influenciam a interação com os demais. No reconhecimento de suas potencialidades, o praticante encontra espaço de atuação sem estar limitado a padrões de movimento pautados em virtuosismo e em modelos corporais rígidos.

\section{Considerações finais}

No presente texto, busquei identificar as práticas citadas enquanto menos restritivas ao ampliarem o acesso a artistas com suas mais diversas possibilidades corporais, e proporem um aspecto relacional a partir de pressupostos de interação entre os participantes que mobiliza dinâmicas de privilégio e de poder. Tendo em vista o artista com deficiência, as práticas somáticas podem ser um meio interessante de assumir a potencialidade dos corpos a partir do reconhecimento e alargamento de sentidos advindos das heranças culturais e das construções sociais da deficiência. Neste sentido, a área das Artes Cênicas já conta com alguns estudos que abordam as práticas de educação somática em propostas artístico-pedagógicas envolvendo pessoas com e sem deficiência (ALMEIDA, 2012; GARROCHO, 2007; SILVEIRA, 2009).

Abordagens corporais mais acessíveis utilizadas em processos de criação e que promovem a participação de pessoas com deficiência nas artes da cena podem nos levar a refletir sobre a participação de futuros artistas com deficiência nos cursos da área de artes nas instituições de ensino superior. Esse aspecto, certamente, seria 
tema de outro estudo, porém é válido que o questionando possa nos acompanhar desde já. Este texto, conforme apresentado em seu início, não tem a intenção de encerrar o assunto. Assim, espero que as abordagens aqui reconhecidas e analisadas possam impulsionar outros estudos, ampliando as referências sobre práticas corporais - assim como espaços de ensino e criação - acessíveis ao público de pessoas com deficiência.

\section{Referências}

ALBRIGHT, Ann Cooper. À corps ouverts. Changement et échange d'identités dans la Capoeira et le contact improvisation. Protée, v. 29, n. 2, p. 39-46, 2001. Disponível em: <http://id.erudit.org/ iderudit/030624ar>. Acesso em: 12 ago. 2016.

ALMEIDA, Renata M. Fonseca de. Não ver e ser visto em dança: análise comparativa entre o Potlach Grupo de Dança e a Associação / Cia de Ballet de Cegos. Belo Horizonte: Programa de Pós-Graduação em Artes/Universidade Federal de Minas Gerais, 2012. Dissertação (Mestrado em Artes).

AMIR, Leora. Integration is an art: necessary dialogue on disabled-nondisabled integration(s), power dynamics and partnership in physically integrated dance, dance theater and community performance. Sacramento: Master of Arts - Theatre Arts/California State University, 2011. Dissertação (Mestrado em Artes - Artes Teatrais).

BATSON, Glenna. Somatic Studies and Dance. International Association for Dance Medicine and Science. Resources papers, 17 set. 2009. Disponível em: <https://c.ymcdn.com/sites/www.iadms.org/ resource/resmgr/resource_papers/somatic_studies.pdf>. Acesso em: 27 jan. 2017.

BRASIL. Decreto no 6949 de 25 de Agosto de 2009. Convenção Internacional sobre os Direitos das Pessoas com Deficiência e seu Protocolo Facultativo. Subchefia para Assuntos Jurídicos [da] Presidência da República. Brasília, DF, 25, ago., 2009.

FELDENKRAIS, Moshe. Consciência pelo movimento. [Tradução de Daisy A. C. Souza]. São Paulo: Summus, 1977.

GARROCHO, Luiz Carlos. Cartografias de uma improvisação física e experimental. Belo Horizonte: Programa de Pós-Graduação em Artes/Universidade Federal de Minas Gerais, 2007. Dissertação (Mestrado em Artes).

HANNA, Thomas. Dicionnary definition of the word somatics. Somatics: Magazine-Journal of the Bodily Arts and Sciences, v. IV, n. 2, 1983.

KUPPERS, Petra. Educação acessível: estética, corpos e deficiência. Revista Cena, Porto Alegre, UFRGS, n. 15, s/p, 2014.

PAXTON, Steve. Corpos em liberdade (depoimento). Revista E, n. 108. São Paulo, maio 2006. Disponível em: <http://www.sescsp.org.br/online/artigo/3145_DEPOIMENTOS\#/tagcloud=lista>. Acesso em: 12 ago. 2016.

SILVEIRA, Saulo Silva da. Técnica e $(m)$ Criação Somática: uma proposta corporal para artistas cênicos com (d)eficiência física através dos Princípios e Fundamentos Corporais Bartenieff. Salvador: Programa de Pós-Graduação em Artes Cênicas/ Universidade Federal da Bahia, 2009. Dissertação (Mestrado em Artes Cênicas).

TEIXEIRA, Ana Carolina Bezerra. Deficiência em cena: desafios e resistências da experiência corporal para além das eficiências dançantes. Salvador: Programa de Pós-Graduação em Artes Cênicas/ Universidade Federal da Bahia, 2010. Dissertação (Mestrado em Artes Cênicas). 
TURSI, Rafael. Meu corpo, teu corpo e este outro: visitando os processos criativos do Projeto PÉS. Brasília: Programa de Pós-Graduação em Artes/Universidade de Brasília, 2014. Dissertação (Mestrado em Artes).

VENDRAMIN, Carla. Diversas danças - diversos corpos: discursos e práticas da dança no singular e no plural. DO CORPO: Ciências e Artes, Caxias do Sul, UCS, v. 1, n. 3, p. 1-18, 2013.

\section{Marcia Berselli}

É professora do Curso de Licenciatura em Teatro da Universidade Federal de Santa Maria (UFSM); doutoranda em Artes Cênicas pelo Programa de Pós-Graduação em Artes Cênicas da Universidade Federal do Rio Grande do Sul (UFRGS) com a pesquisa Procedimentos criativos de amplo acesso: (des) habilidades em cena a partir da flexibilização do acesso às artes cênicas, sob orientação da Profa. Dra. Marta Isaacsson.

E-mail: marcia.berselli@ufsm.br

Currículo: http://lattes.cnpq.br/0739122615811316

Recebido em 15 de fevereiro de 2017 Aceito em 19 de abril de 2017 